\title{
Peroneal artery perforator flap for the treatment of chronic lower extremity wounds
}

\author{
Liang Cheng, Xiaqing Yang, Tingxiang Chen and Zhijie Li ${ }^{*}$ (D
}

\begin{abstract}
Background: Reconstruction of chronic lower extremity wounds remains challenging. These wounds are mainly associated with diabetes mellitus, infections, and osteomyelitis. Although several reconstructive techniques are available, the peroneal artery perforator flap has unique advantages.

Methods: In this study, we discuss our experiences with peroneal artery perforator flaps in 55 patients who had suffered from chronic lower limb wounds. The size of the defect, comorbidities, etiology, flap size, and complications were recorded and analyzed based on a retrospective chart review.

Results: All 55 flaps survived. In two cases, small superficial necrosis occurred, one of which healed with conservative treatment and the other was reconstructed with split thickness skin grafts. Partial necrosis was observed in nine cases, seven of which were covered with split thickness skin grafts and the remaining two sutured directly after adequate debridement. Vascular compromise was observed in one patient, which was salvaged successfully by performing an exploratory procedure and releasing a few sutures. No complications were seen in the remaining 44 cases.
\end{abstract}

Conclusion: The peroneal artery perforator flap is a reliable option for reconstruction of chronic lower extremity wounds.

Keywords: Peroneal artery perforator flap, Chronic lower extremity wounds, Reconstructive

\section{Background}

Reconstruction of chronic lower extremity wounds remains a challenging task, particularly in patients with circulation problems. Various options including local flaps, free flaps, and muscle flaps have been used for reconstruction in these cases; however, rebuilding techniques to enhance outcomes have not been identified [1-6]. Before utilizing local flaps, free flaps, or pedicle flaps, surgeons should reduce the amount of soft tissue and determine the clinical application subjected to their limited reach. In 1984, Yoshimura et al. [7] introduced the peroneal artery perforator flap. The perforator flap is based on the concept that skin can be divided into angiosomes [8]. Indeed, for the perforator approach, the recipient area has a flexible rotation with remarkable applicability, and the flap is nourished by perforator vessels

\footnotetext{
*Correspondence: 18767168160@163.com

Department of Hand and Plastic Surgery, The Second Affiliated Hospital and Yuying Children's Hospital of Wenzhou Medical University, 109 Xue Yuan Xi Road, Wenzhou, Zhejiang, China
}

(c) The Author(s). 2017 Open Access This article is distributed under the terms of the Creative Commons Attribution 4.0 International License (http://creativecommons.org/licenses/by/4.0/), which permits unrestricted use, distribution, and reproduction in any medium, provided you give appropriate credit to the original author(s) and the source, provide a link to the Creative Commons license, and indicate if changes were made. The Creative Commons Public Domain Dedication waiver (http://creativecommons.org/publicdomain/zero/1.0/) applies to the data made available in this article, unless otherwise stated.

\section{Methods}

This study was performed in accordance with the ethical standards of the Declaration of Helsinki. Ethics approval that arise from a deep vascular system [9]. Compared with the traditional flap or workhorse flap (such as the anterolateral thigh flap), the peroneal artery perforator flap decreases bleeding, preserves muscle function, has a multiform flap design, and enhances mobility of the flap [10]. Besides, a peroneal septocutaneous or musculocutaneous perforator stems from the parent vessel, which directly supplies the overlying skin, and the flap helps preserve the peroneal vessel system. Due to these advantages, peroneal artery perforator flaps are a suitable choice for the treatment of chronic lower

In this report, we describe our experiences with 55 patients suffering from chronic lower extremity wounds who underwent surgical reconstruction with peroneal artery perforator flaps. 
was obtained through the Hospital's Regional Ethics Committee, and all patients gave informed consent prior to inclusion in the study.

A retrospective analysis was performed using the medical records of 55 patients who underwent lower extremity wound reconstruction using peroneal artery perforator flaps between May 2008 and September 2015. For each patient, the following data were collected and recorded: age, sex, etiology, size of the defect, comorbidities, dimension of the flap, complications, and followup. The patients included 43 males and 12 females, and their ages varied from 3 to 78 years, with an average age of 48.87 years. A total of 22 patients suffered from open tibia/fibula/ankle/calcaneus fractures with associated infection; open fracture in 14, machine crash in 1, crashinjury in 6 , osteomyelitis in 4 , tumble in 1 , scald in 1 , skin ulcer in 1, chronic tophus gout in 1, foot mass in 1, and 3 cases of an Achilles tendon rupture associated with infection. The soft-tissue defect was located on the calcaneus in 7 cases, the malleolar area in 16 cases, around the knee in 4 cases, the acrotarsium area in 10 cases, and the lower extremity in 18 cases. Defect sizes ranged from 1.5 to $300 \mathrm{~cm}^{2}$. The wounds were debrided an average of 2.98 times (range, 1-8 times). All cases were performed with vigorous debridement, after which the peroneal artery perforator flaps were applied.

\section{Surgical technique}

A Doppler probe was used preoperatively to locate the peroneal artery and the most appropriate perforator vessel. Under a combined spinal epidural analgesia, patients were placed in a supine position with the injured legs slightly abducted and the thigh under tourniquet control. After vigorous debridement, the outline of the flap was drawn based on the size and shape of the defect. Flap design and orientations around the sited perforators ensured adequate length and width so that the flap could be harvested. Flap dissection was initiated along the anterior side of the flap down to the crural fascia and was performed in the same fashion on the posterior side. Subfascial dissection was performed laterally until the septocutaneous perforator or musculocutaneous perforator was identified. Because the process of the musculocutaneous perforator is often twisted, dissection is performed punctiliously to avoid perforator injury. After confirming that the perforator was a branch of the peroneal artery, the flap was harvested. The raised flap was able to rotate around the perforator and adapt to the defect. In a small number of cases, split thickness skin graft (STSG) derived from the thigh was required to cover the defect with the peroneal artery perforator flap, and most donor sites were closed. Over-tight bandaging was avoided to limit vascular embarrassment, and a window was made in the dressing to observe the flap. Before ambulation was achieved, anticoagulation treatment with low weight molecular heparin was introduced. Postoperatively, all cases received appropriate antibiotic therapy and symptomatic rehydration support treatment. All patients were coached periodically until the wound site was achieved and the donor had healed. Generally, flap sutures were dismantled on the 14th postoperative day.

\section{Case 4}

A 50-year-old female suffered a soft tissue defect around the ankle joint due to a traffic accident. After radical debridement, a peroneal artery perforator flap measuring approximately $20 \mathrm{~cm} \times 7 \mathrm{~cm}$ was elevated from the ipsilateral lower leg. The flap was subsequently inset into the defect at 150 degrees based on the pivot of the perforator. The donor site was closed by combining the split thickness skin graft. Postoperative recovery was uneventful; the flap survived completely. A satisfactory result was obtained at 1-year follow-up (Fig. 1).

\section{Case 15}

A 38-year-old man developed traumatic bone exposure with a soft tissue defect after suffering an open tibia and fibula fracture. After debridement of the necrotic tissue, a peroneal artery perforator flap measuring $15 \mathrm{~cm} \times 3 \mathrm{~cm}$ was raised from the same leg and transferred to the defect. The donor site was closed. Postoperatively, the distal part of the flap showed partial necrosis and was treated with dressing changes. Fortunately, the flap survived, and the patient was satisfied with the appearance (Fig. 2).

\section{Case 20}

A 46-year-old man had a traumatic soft tissue loss of the lower leg with exposure of the bone. To restore function, a peroneal artery perforator flap measuring $18 \mathrm{~cm} \times 4 \mathrm{~cm}$ was harvested and transferred to the defect. The donor site was closed, and the transferred tissues survived completely (Fig. 3).

\section{Results}

From May 1997 to September 2015, 55 peroneal artery perforator flaps were performed in patients with chronic lower extremity wounds. The details of all patients are presented in Table 1. The average operating time was $132 \mathrm{~min}$, and the flaps ranged in size from 1.5 to $260 \mathrm{~cm}^{2}$. All 55 flaps survived. In two cases, small superficial necrosis occurred, one of which healed with conservative treatment and the other reconstructed with STSG. Partial necrosis was observed in eight cases, six of which were covered with STSG and the remaining two directly sutured after debridement. Vascular compromise was only observed in one patient and was salvaged by performing an exploratory procedure and 


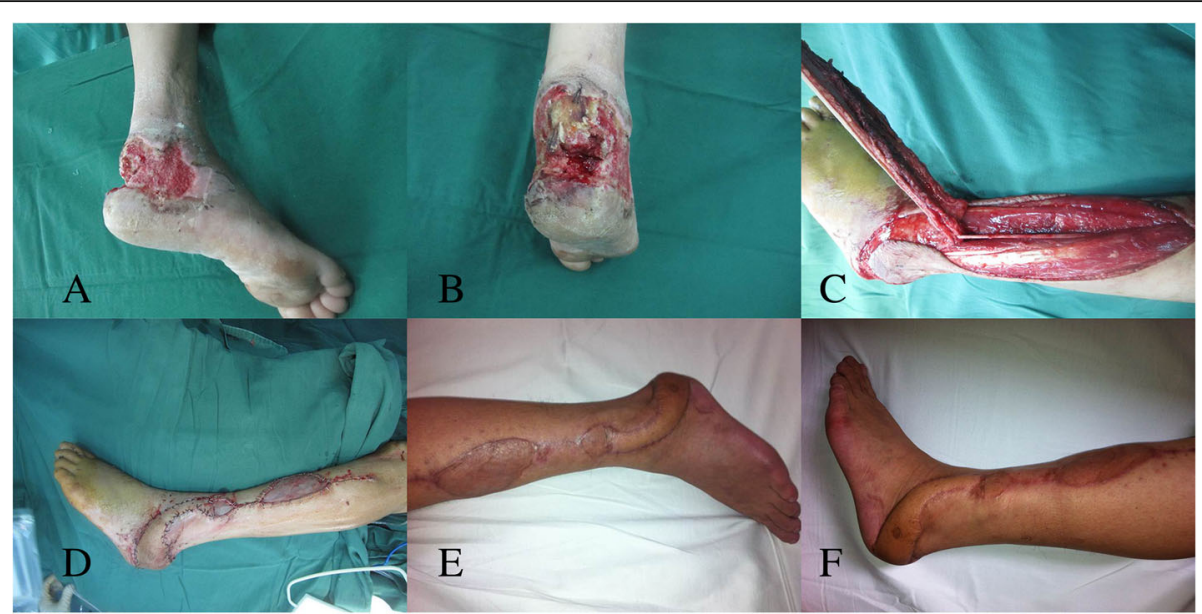

Fig. 1 a, b A defect with exposed calcaneus in the heel. c Harvesting the peroneal artery perforator flap. $\mathbf{d}$ Early postoperative view. e Appearance 6 months after operation. $\mathbf{f}$ Follow-up at 12 months

releasing a few sutures. In one patient, the ultra-thin flap procedure was performed at 6 months postoperatively due to a bulky appearance. No complications were seen in the remaining 43 cases. The length of hospital stay ranged from 7 to 80 days (average of 33.36 days). Follow-up ranged from 7 to 45 months, with an average of 25.9 months. Ultimately, all patients were satisfied with the functional results and could walk comfortably.

\section{Discussion}

Reconstruction of soft tissue defects overlying the lower limbs remains a significant challenge, as this region is typically associated with exposure of tendon or bone and metal fixation of fractures. Wound healing is markedly prolonged (leading to chronic wounds) due to a lack of adequate soft tissue coverage and a decrease in distal perfusion of the lower limbs. Since the freestyle perforator construct and perforasome theory were proposed, the use of local flaps has increased [11]. In addition, because adjacent tissue is typically involved and massive edema formation prevents adequate mobilization, access to a local flap is limited. However, free tissue transfer can be an excellent option if local tissue transfer with a pedicled or propeller flap is unsuitable. Although free tissue transfer is the traditional option for lower extremity reconstruction, it is tedious and requires complex technical expertise [12]. Muscle flaps have been used for decades due to their rich blood supply and anti-infection capabilities. In addition, muscle tissues are not only suitable for the obliteration of dead space in complex three-dimensional defects, but can expedite bone healing during the early phases of repair. However, the

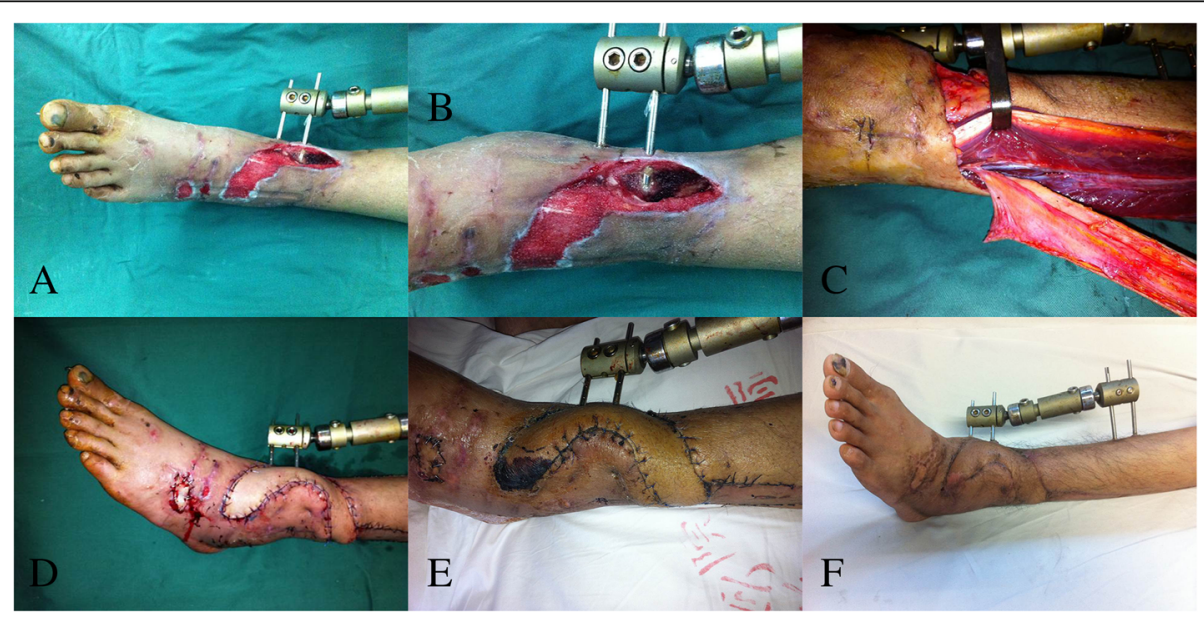

Fig. 2 a, b A defect with exposed fracture in the distal of lower limb. c Raising the peroneal artery perforator flap. d Early postoperative view. e Appearance 10 days after operation. f Follow-up at 12 months 


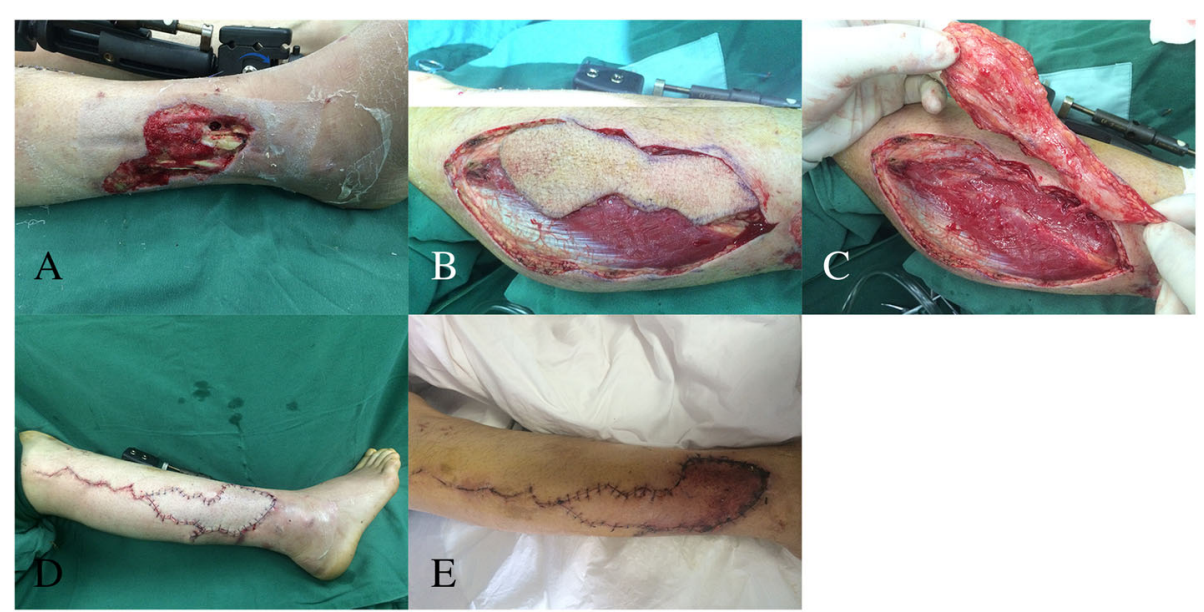

Fig. 3 a A defect with exposed fracture in the distal of lower limb. b Dissected the peronal artery perforator flap. c Elevating the peronal artery perforator flap. $\mathbf{d}$ Early postoperative view. e Appearance 7 days after operation

application of muscle flaps gives rise to an unflattering appearance, interferes with daily functions, or secondary debulking procedures [13-15] leading to prolonged hospital time, additional suffering, and higher cost.

With recent progress in perforator techniques, attention is directed towards improved methods of reconstruction. The peroneal artery perforator flap is a promising option for reconstruction of the lower limbs, especially for coverage of ankle and heel defects $[16,17]$.

In our series, the necrosis rate of the peroneal artery perforator flap was $18.2 \%(N=10$, including nine men and one woman; mean age, 58.2 years) (Table 2). In the series, seven patients have DM (diabetes mellitus), four patients have HTN (hypertension), and four patients have arteriopathy. Bekara et al. [18] identified the following risk factors: age older than 60 years, diabetes, and arteriopathy, which play a significant role in the rebuilding procedure. In our study, these factors also played an important role in flap necrosis. In addition, all ten cases had smoking histories. We believe smoking is an important risk factor that jeopardized the perforators during rotation. Hence, before the procedure, the clinical history should be explored and the smoking status should be documented. Postoperatively, the wound should be monitored periodically. Flap necrosis occurred distally and superficially with small ranges (less than $4 \mathrm{~cm}^{2}$ ); dressing changes may address this issue. If the range is larger, adequate debridement or STSG may be suitable.

According to the authors' experiences, the ratio of flap length to width, the condition of the pedicle, and the proper thinning of flap may have an important influence on flap survival. As we all know, the length-to-width ratio of random skin flap must not exceed 2:1; otherwise, ischemia and necrosis of the distal flap may occur [19]. However, the length-to-width ratio of perforator flap also existed. In our series, we found that the ratio should not exceed 8:1. When the pattern of the harvested flap exceeded the limit, the distal blood supply would be affected. Besides, the pedicle was of equal importance in perforator flap survival. When the pedicle was identified, soft tissue around it must be wiped off thoroughly under the premise that blood supply would not be affected because during the rotation of the perforator, the redundant tissue might menace the blood transmission leading to descend flap survival rate. Occasionally, two or more perforators appeared at the same time. In our experiences, more perforators were not good for flap survival; on the contrary, they may be harmful, for the reason that one of which was likely to twist or surrounding tissue oppress the pedicle resulting in flap failure in the rotation process. Once flap blood supply was influenced, it was necessary to take out stitches and put the harvested flap back instantly, and a delay transfer procedure was done until the blood supply of the harvested flap improved obviously. Therefore, we usually reserve only one perforator, and it must be the distal one in order to gain adequate blood supply, increase flap survival rate, and enhance the repairable scope. With regard to small defect or relative wide defect (length-to-width ratio less than 4:1), fearless debulking procedure can be done because of the good capillary network, while to big defect or relative long defect (length-to-width ratio more than 4:1), cautious debulking procedure can be done or only margin fat granule can be removed. Moreover, vasodilator was not used in any patient, and we concluded that flap survival may not be related to the application of vasodilator.

However, there were several limitations in our study, particularly the inadequate data collection such as the length of the pedicle, the location of the pedicle, and 
Table 1 Data of the patients

\begin{tabular}{|c|c|c|c|c|c|c|c|c|}
\hline $\begin{array}{l}\text { Patient } \\
\text { No. }\end{array}$ & $\begin{array}{l}\text { Age/ } \\
\text { gender }\end{array}$ & Etiology & $\begin{array}{l}\text { Size of defect } \\
(\mathrm{cm})\end{array}$ & Comorbidities & $\begin{array}{l}\text { Dimension of } \\
\text { flap }(\mathrm{cm})\end{array}$ & Complication & Secondary procedure & $\begin{array}{l}\text { Follow-up } \\
\text { (months) }\end{array}$ \\
\hline 1 & $76 / \mathrm{M}$ & OFSI & $6 \times 4$ & HTN & $4.5 \times 2$ & None & None & 18 \\
\hline 2 & $67 / M$ & ATRSI & $4 \times 6$ & Arteriopathy & $4 \times 6.5$ & None & None & 13 \\
\hline 3 & $7 / \mathrm{M}$ & OFSI & $4 \times 5$ & None & $4 \times 5$ & None & None & 10 \\
\hline 4 & $50 / F$ & Open fracture & $20 \times 4$ & HTN & $20 \times 7$ & None & None & 7 \\
\hline 5 & $44 / F$ & Skin ulcer & $6 \times 6$ & DM & $5 \times 5$ & None & None & 20 \\
\hline 6 & $54 / \mathrm{M}$ & Open fracture & $8 \times 6$ & DM/arteriopathy & $8 \times 6$ & Partial necrosis & Debridement, suture & 19 \\
\hline 7 & $50 / \mathrm{M}$ & OFSI & $4 \times 3$ & None & $4 \times 3$ & None & None & 12 \\
\hline 8 & $47 / M$ & OFSI & $14 \times 8$ & None & $14 \times 8$ & $\begin{array}{l}\text { Bulky } \\
\text { appearance }\end{array}$ & Ultra-thin flap procedure & 23 \\
\hline 9 & $69 / F$ & Osteomyelitis & $12 \times 8$ & DM & $13 \times 8$ & Partial necrosis & STSG & 14 \\
\hline 10 & $59 / M$ & Crush-injured & $10 \times 5.5$ & None & $10 \times 6$ & None & None & 28 \\
\hline 11 & $23 / M$ & Open fracture & $20 \times 10$ & None & $20 \times 13$ & None & None & 27 \\
\hline 12 & $51 / \mathrm{M}$ & Tumble & $10 \times 10$ & None & $9 \times 8$ & None & None & 33 \\
\hline 13 & $67 / F$ & $\begin{array}{l}\text { Foot mass with } \\
\text { secondary infection }\end{array}$ & $3 \times 5$ & Arteriopathy & $5.5 \times 3.5$ & None & None & 31 \\
\hline 14 & $28 / M$ & Crush-injured & $3 \times 4$ & None & $3 \times 4$ & $\begin{array}{l}\text { Vascular } \\
\text { compromise }\end{array}$ & $\begin{array}{l}\text { Exploratory procedure, } \\
\text { releasing of a few sutures }\end{array}$ & 45 \\
\hline 15 & $38 / M$ & OFSI & $6 \times 2$ & None & $15 \times 3$ & None & None & 19 \\
\hline 16 & $55 / \mathrm{M}$ & OFSI & $6 \times 5$ & None & $6 \times 5$ & None & None & 25 \\
\hline 17 & $51 / \mathrm{M}$ & Open fracture & $11 \times 4$ & None & $12 \times 6$ & None & None & 9 \\
\hline 18 & $48 / \mathrm{M}$ & OFSI & $8 \times 10$ & None & $12 \times 9$ & None & None & 22 \\
\hline 19 & $63 / M$ & OFSI & $15 \times 7$ & DM & $15 \times 8$ & None & None & 37 \\
\hline 20 & $36 / M$ & OFSI & $15 \times 8$ & None & $12 \times 6$ & None & None & 18 \\
\hline 21 & $30 / F$ & Open fracture & $6 \times 7$ & None & $6 \times 6$ & None & None & 9 \\
\hline 22 & $46 / M$ & OFSI & $8 \times 5$ & None & $18 \times 4$ & None & None & 41 \\
\hline 23 & $66 / M$ & OFSI & $6 \times 3$ & HTN & $7 \times 4$ & Partial necrosis & STSG & 24 \\
\hline 24 & $40 / M$ & ATRSI & $8 \times 9$ & None & $8 \times 9$ & None & None & 27 \\
\hline 25 & $37 / M$ & ATRSI & $3 \times 2$ & None & $4 \times 3$ & None & None & 22 \\
\hline 26 & $44 / M$ & Machine crashed & $6 \times 6$ & HTN & $8 \times 6$ & Partial necrosis & STSG & 43 \\
\hline 27 & $62 / M$ & OFSI & $9 \times 4$ & Arteriopathy & $9 \times 4$ & None & None & 36 \\
\hline 28 & $44 / M$ & Open fracture & $5 \times 15$ & Arteriopathy & $5 \times 25$ & $\begin{array}{l}\text { Superficial } \\
\text { necrosis }\end{array}$ & Dressing change & 30 \\
\hline 29 & $60 / M$ & $\begin{array}{l}\text { Chronic tophus } \\
\text { gout }\end{array}$ & $3 \times 4$ & Chronic tophus & $5 \times 6$ & Partial necrosis & STSG & 38 \\
\hline 30 & $58 / F$ & OFSI & $1 \times 1.5$ & None & $1 \times 1.5$ & None & None & 26 \\
\hline 31 & $48 / M$ & OFSI & $10 \times 8$ & DM & $12 \times 10$ & $\begin{array}{l}\text { Superficial } \\
\text { necrosis }\end{array}$ & STSG & 16 \\
\hline 32 & $63 / M$ & Crush-injured & $8 \times 8$ & None & $8 \times 9$ & None & None & 38 \\
\hline 33 & $53 / F$ & Open fracture & $8 \times 5$ & None & $8 \times 7$ & None & None & 24 \\
\hline 34 & $36 / M$ & OFSI & $5 \times 4$ & None & $6 \times 5$ & None & None & 30 \\
\hline 35 & $71 / M$ & Osteomyelitis & $5 \times 4$ & $\mathrm{DM} / \mathrm{HTN}$ & $5 \times 4$ & None & None & 22 \\
\hline 36 & $63 / F$ & Open fracture & $8 \times 4$ & None & $9 \times 4.5$ & None & None & 28 \\
\hline 37 & $78 / \mathrm{M}$ & Open fracture & $15 \times 15$ & $\begin{array}{l}\text { DM/HTN/ } \\
\text { arteriopathy }\end{array}$ & $15 \times 10$ & Partial necrosis & STSG & 42 \\
\hline 38 & $47 / M$ & Open fracture & $20 \times 15$ & None & $20 \times 10$ & None & None & 36 \\
\hline 39 & $3 / F$ & Open fracture & $12 \times 7$ & None & $12 \times 7$ & None & None & 24 \\
\hline
\end{tabular}


Table 1 Data of the patients (Continued)

\begin{tabular}{|c|c|c|c|c|c|c|c|c|}
\hline $\begin{array}{l}\text { Patient } \\
\text { No. }\end{array}$ & $\begin{array}{l}\text { Age/ } \\
\text { gender }\end{array}$ & Etiology & $\begin{array}{l}\text { Size of defect } \\
(\mathrm{cm})\end{array}$ & Comorbidities & $\begin{array}{l}\text { Dimension of } \\
\text { flap }(\mathrm{cm})\end{array}$ & Complication & Secondary procedure & $\begin{array}{l}\text { Follow-up } \\
\text { (months) }\end{array}$ \\
\hline 40 & $56 / M$ & OFSI & $6 \times 4$ & None & $6 \times 4$ & None & None & 22 \\
\hline 41 & $60 / M$ & OFSI & $5 \times 2$ & None & $5 \times 3$ & None & None & 33 \\
\hline 42 & $20 / M$ & Open fracture & $12 \times 8$ & None & $16 \times 8.5$ & None & None & 27 \\
\hline 43 & $72 / \mathrm{M}$ & OFSI & $10 \times 5$ & DM/HTN & $12 \times 6$ & None & None & 37 \\
\hline 44 & $60 / \mathrm{M}$ & OFSI & $3 \times 11$ & None & $3 \times 11$ & None & None & 27 \\
\hline 45 & $61 / \mathrm{M}$ & OFSI & $4 \times 6$ & DM/arteriopathy & $5 \times 7$ & Partial necrosis & $\begin{array}{l}\text { Debridement, } \\
\text { suture }\end{array}$ & 18 \\
\hline 46 & $60 / F$ & OFSI & $4 \times 4$ & None & $4 \times 4$ & None & None & 22 \\
\hline 47 & $47 / M$ & Open fracture & $12 \times 10$ & None & $12 \times 10$ & None & None & 23 \\
\hline 48 & $44 / F$ & OFSI & $12 \times 10$ & None & $16 \times 10$ & None & None & 47 \\
\hline 49 & $53 / \mathrm{M}$ & Osteomyelitis & $7 \times 5$ & None & $7 \times 5$ & None & None & 28 \\
\hline 50 & 49/M & Osteomyelitis & $4 \times 5$ & None & $5 \times 4$ & None & None & 34 \\
\hline 51 & $5 / F$ & Scald & $5 \times 6$ & None & $5 \times 7$ & None & None & 19 \\
\hline 52 & $44 / M$ & Crush-injured & $5 \times 7$ & None & $5 \times 7$ & None & None & 31 \\
\hline 53 & $28 / \mathrm{M}$ & Crush-injured & $15 \times 10$ & None & $15 \times 10$ & None & None & 27 \\
\hline 54 & $39 / \mathrm{M}$ & Open fracture & $15 \times 7$ & None & $15 \times 8$ & None & None & 16 \\
\hline 55 & $58 / \mathrm{M}$ & Crush-injured & $15 \times 10$ & DM/HTN & $15 \times 10$ & Partial necrosis & STSG & 7 \\
\hline
\end{tabular}

Notes: $M$ male, $F$ female, OFSI open fractures with secondary infection, ATRSI Achilles tendon rupture with secondary infection, DM diabetes mellitus, HTN hypertension, STSG splint thickness skin graft

function and appearance quantized evaluation. In our further research, these limitations will be put in an important position.

In the lower limbs involving the anterior tibial area, ankle, heel area, or the dorsum of the foot, thin, pliable, durable, and gliding soft tissue transfer is the preferred option to achieve a satisfactory esthetic outcome. The peroneal artery perforator flap has these characteristics and is an adequate candidate for this program. In addition, the peroneal artery perforator flap is a time efficient, esthetic, and reliable procedure with lower donor site morbidity, enabling significant coverage for chronic infection, and it can sustain ancillary surgical procedures. Previous studies have shown that the settlement of chronic osteomyelitis and infected wounds is dependent on adequate debridement and extermination of dead spaces; in contrast, the type of flap used to reconstruct lower extremity defects has little impact on the ultimate result [20-22]. Aggressive debridement and eradication of dead spaces with an effective flap must be used when treating chronic wounds.

In summary, the peroneal artery perforator flap is a beneficial and reliable technique; it is appropriate for

Table 2 Patients occurred necrosis

\begin{tabular}{|c|c|c|c|c|c|c|}
\hline Patient No. & Age/gender & Etiology & Smoke history & Size of defect $(\mathrm{cm})$ & Comorbidities & Secondary procedure \\
\hline 6 & $54 / \mathrm{M}$ & Open fracture & Yes & $8 \times 6$ & DM/Arteriopathy & Debridement, suture \\
\hline 9 & $69 / F$ & Osteomyelitis & Yes & $12 \times 8$ & DM & STSG \\
\hline 23 & $66 / M$ & OFSI & Yes & $6 \times 3$ & HTN & STSG \\
\hline 26 & $44 / \mathrm{M}$ & Machine crashed & Yes & $6 \times 6$ & HTN & STSG \\
\hline 28 & $44 / M$ & Open fracture & Yes & $5 \times 15$ & Arteriopathy & Dressing change \\
\hline 29 & $60 / \mathrm{M}$ & Chronic tophus gout & Yes & $3 \times 4$ & Chronic tophus & STSG \\
\hline 31 & $48 / \mathrm{M}$ & OFSI & Yes & $10 \times 8$ & DM & STSG \\
\hline 37 & 78/M & Open fracture & Yes & $15 \times 15$ & DM/HTN/arteriopathy & STSG \\
\hline 45 & $61 / \mathrm{M}$ & OFSI & Yes & $4 \times 6$ & DM/arteriopathy & Debridement, suture \\
\hline 55 & $58 / \mathrm{M}$ & Crush-injured & Yes & $15 \times 10$ & DM/HTN & STSG \\
\hline
\end{tabular}

Notes: $M$ male, $F$ female, OFSI open fractures with secondary infection, DM diabetes mellitus, HTN hypertension, STSG splint thickness skin graft 
small to moderate extremity defects, especially in the ankle and heel.

\section{Conclusion}

The peroneal artery perforator flap is a reliable and reproducible procedure providing low postoperative morbidity, good daily functions, and relatively satisfactory esthetic results, without sacrificing any major vessels or nerves. It is intended to be a suitable alternative for the reconstruction of lower limb defects. Because microvascular anastomosis is not required, the flap is less time consuming and has a lower risk of vascular thrombosis compared with other complex techniques. Hence, the peroneal artery perforator flap is a reliable option for the treatment of chronic lower extremity wounds.

\section{Abbreviations}

ATRSI: Achilles tendon rupture with secondary infection; DM: Diabetes mellitus; F: Female; HTN: Hypertension; M: Male; OFSI: Open fractures with secondary infection; STSG: Splint thickness skin graft

\section{Acknowledgements}

The authors would like to thank the Natural Science Foundation of Zhejiang Province (No. Y16H060039).

\section{Funding}

This article was supported by the Natural Science Foundation of Zhejiang Province (No. Y16H060039). It payed the fee for the English language service.

\section{Availability of data and materials}

Data sharing is not applicable to this article as no datasets were generated or analyzed during the current study.

\section{Authors' contributions}

$\mathrm{CL}$ designed the study and drafted the manuscript. TXC collected the data XQY participated in the design and data collection. ZJL conceived of the study, participated in its design and coordination, and helped to draft the manuscript. All authors read and approved the final manuscript.

\section{Authors' information}

$\mathrm{CL}, \mathrm{TXC}, \mathrm{XQY}$, and ZJL concentrated on rebuilding soft tissue defects in extremities.

\section{Ethics approval and consent to participate}

The use of the data from all patients has been approved by The Second Hospital of Wenzhou Medical University Research Ethics Committee.

\section{Consent for publication}

The patients agreed for the study to be published.

\section{Competing interests}

The authors declare that they have no competing interests.

\section{Publisher's Note}

Springer Nature remains neutral with regard to jurisdictional claims in published maps and institutional affiliations.

Received: 3 May 2017 Accepted: 2 November 2017

Published online: 10 November 2017

\section{References}

1. Checcucci G, Galeano M, Zucchini M, Zampetti PG, Ceruso M. Reverse flow first dorsal metacarpal artery flap for covering the defect of distal thumb. Microsurgery. 2014;34(4):283-6.
2. Wang X, Mei J, Pan J, Chen H, Zhang W, Tang M. Reconstruction of distal limb defects with the free medial sural artery perforator flap. Plast Reconstr Surg. 2013;131(1):95-105.

3. Zhu YL, Yi WMM, Xiao-Qing HMM, Min ZMM, Li FB, Xu YQ. Foot and ankle reconstruction: an experience on the use of 14 different flaps in 226 cases. Microsurgery. 2013;33(8):600-4

4. Chen C, Tang P, Zhang X. The dorsal homodigital island flap based on the dorsal branch of the digital artery: a review of 166 cases. Plast Reconstr Surg. 2014;133(4):519e-29e.

5. Liu J, Zheng H. Free distal ulnar artery perforator flaps for the reconstruction of a volar defect in fingers. J Plast Reconstr Aesthet Surg. 2014;67(11):1557-63.

6. Hallock GG. Medial sural artery perforator free flap: legitimate use as a solution for the ipsilateral distal lower extremity defect. J Reconstr Microsurg. 2014;30(3):187-92.

7. Yoshimura M, Imura S, Shimamura K, Yamauchi S, Nomura S. Peroneal flap for reconstruction in the extremity: preliminary report. Plast Reconstr Surg. 1984;74(3):402-9.

8. Taylor Gl, Pan WR. Angiosomes of the leg: anatomic study and clinical implications. Plast Reconstr Surg. 1998;102(3):599-616.

9. Blondeel PN, Van Landuyt KH, Monstrey SJ, et al. The "Gent" consensus on perforator flap terminology: preliminary definitions. Plast Reconstr Surg. 2003:112(112):1378-83.

10. Tanaka K, Matsumura H, Miyaki T, Watanabe K. An anatomic study of the intermuscular septum of the lower leg; branches from the posterior tibial artery and potential for reconstruction of the lower leg and the heel. J Plast Reconstr Aesthet Surg. 2006;59(8):835-8.

11. Wei FC, Mardini S. Free-style free flaps. Plast Reconstr Surg. 2004;114(4):910-6.

12. Levin LS. Foot and ankle soft-tissue deficiencies: who needs a flap? Am J Orthop. 2006;35(1):11-9.

13. Chowdary RP Jr, Murphy RX. Delayed debulking of free muscle flaps for aesthetic contouring debulking of free muscle flaps. Br J Plast Surg. 1992;45(1):38-41.

14. AF P, Unal MB, Cansü E. The reconstruction of foot soft tissue defects by tangential debulking of the latissimus dorsi flap. J Reconstr Microsurg. 2011:27(4):211-4.

15. Parrett BM, Boumerhi JS, Buntic RF, Safa B, Buncke GM, Brooks D. Refining outcomes in dorsal hand coverage: consideration of aesthetics and donor-site morbidity. Plast Reconstr Surg. 2010;126(5):1630-8.

16. $\mathrm{TC} L$, Lin $\mathrm{CH}$, Lin $\mathrm{CH}$, Lin $Y T$, Chen RF, Wei FC. Versatility of the pedicled peroneal artery perforator flaps for soft-tissue coverage of the lower leg and foot defects. J Plast Reconstr Aesthet Surg. 2011;64(3):386-93.

17. Ribuffo D, Atzeni ML, Guerra M, et al. Clinical study of peroneal artery perforators with computed tomographic angiography: implications for fibular flap harvest. Anat Clin. 2010:32(4):329-34.

18. Bekara F, Herlin C, Mojallal A, et al. A systematic review and meta-analysis of perforator-pedicled propeller flaps in lower extremity defects. Plast Reconstr Surg. 2016;137(1):314-31.

19. Cai L, Huang W, Lin D. Effects of traditional Chinese medicine Shuxuetong injection on random skin flap survival in rats. ScientificWorldJournal. 2014;2014:816545.

20. Hong JP, Shin HW, Kim JJ, Wei FC, Chung YK. The use of anterolateral thigh perforator flaps in chronic osteomyelitis of the lower extremity. Plast Reconstr Surg. 2005;115(1):142-7.

21. Rodriguez ED, Bluebond-Langner R, Copeland C, Grim TN, Singh NK, Scalea T. Functional outcomes of posttraumatic lower limb salvage: a pilot study of anterolateral thigh perforator flaps versus muscle flaps. J Trauma. 2009:66(5):1311-4.

22. Yildirim S, Gideroğlu K, Aköz T. The simple and effective choice for treatment of chronic calcaneal osteomyelitis: neurocutaneous flaps. Plast Reconstr Surg 2003;111(2):761-2 